\title{
TRANSFORMASI PENGELOLAAN PERAIRAN UMUM DARATAN DI KABUPATEN OGAN KOMERING ILIR
}

\author{
Radityo Pramoda dan Zahri Nasution \\ Balai Besar Penelitian Sosial Ekonomi Kelautan dan Perikanan \\ JI. KS. Tubun Petamburan VI Jakarta 10260 \\ Telp. (021) 53650162, Fax. (021) 53650159 \\ Diterima 21 Februari 2011 - Disetujui 21 Mei 2011
}

\begin{abstract}
ABSTRAK
Penelitian ini bertujuan untuk mengkaji implementasi dan antisipasi dampak ketentuan baru Peraturan Daerah (PERDA) Ogan Komering Ilir (OKI) No. 9/2008 tentang Pengelolaan Lebak, Lebung, dan Sungai di Kabupaten Ogan Komering llir, yang menjadi otonomi desa. Penelitian ini menggunakan metode deskriptif eksploratif melalui pendekatan historis kasuistik yang didukung data primer dan sekunder. Hasil penelitian menunjukkan bahwa transformasi pengelolaan perairan umum daratan dengan berlakunya Perda OKI No. 9/2008 memberikan akses yang lebih besar kepada masyarakat untuk memanfaatkan sumber daya ikan. Kewenangan yang dimiliki desa menjadi lebih luas dalam mengatur lebak lebung dan sungai. Kurang optimalnya implementasi Perda OKI No. 9/2008 dikarenakan aparatur dan masyarakat Desa Berkat belum siap mengadopsi perubahan nilai serta norma baru. Implikasi kebijakan penelitian ini adalah perlunya meningkatkan kompetensi aparatur desa melalui pelatihan/pendidikan; memberikan sosialisasi secara komprehensif kepada masyarakat; melakukan kontrol dan pendampingan yang konsisten, serta menciptakan komunikasi hukum yang baik dalam menerapkan peraturan baru.
\end{abstract}

Kata Kunci: transformasi, pengelolaan, perairan umum daratan, lebak, lebung, sungai

\section{Abstract:Transformation Management of Inland Waters in Ogan Komering llir District. By: Radityo Pramoda and Zahri Nasution}

This research aimed to review the impact of implementation and anticipate potential impacts of the new provisions of Local Regulation No. 9/2008 on Management of Lebak, Lebung, and Rivers in Ogan llir Komering llir regency, which has become an autonom of the village. Research was conducted using a descriptive-exploratory method, through historical case approach, supported by primary and secondary data. Results show that transformation of the management of inland waters by the enactment of Local Regulation No. 9/2008 provides a greater access to the community to utilize fish resources. Authority of the village was wider than previous system in terms of arranging the lebak lebung and river. Under optimal level of implementation of the Local Regulation No. 9/2008 was due to the apparatus and community unreadines to adopt the values changing in and new norms. Policy implications of this research were as follows improving the competence of village apparatus through training/education; providing comprehensive socialization to the community; doing control and consistent mentoring, and creating a good communication law in applying new regulation.

Keywords: transformation, management, inland waters, lebak, lebung, river 


\section{PENDAHULUAN}

Menurut UU No. 31 Tahun 2004, tentang Perikanan, sebagaimana telah diubah dengan UU No. 45 Tahun 2009, tentang Perubahan atas UU No. 31 Tahun 2004, tentang Perikanan (UU Perikanan), Pasal 6, Ayat (1): pengelolaan perikanan dalam wilayah Republik Indonesia dilakukan untuk tercapainya manfaat yang optimal dan berkelanjutan, serta terjaminnya kelestarian sumber daya ikan. Berkaitan dengan hal tersebut pada tanggal 25 November 2008, Pemerintah Kabupaten Ogan Komering Ilir (OKI), Provinsi Sumatera Selatan (Sumsel), menerbitkan Peraturan Daerah Kabupaten OKI No. 9 Tahun 2008, tentang Pengelolaan Lebak, Lebung, dan Sungai dalam Kabupaten Ogan Komering Ilir (Perda OKI No. 9/2008).

Latar belakang dibentuknya Perda OKI No. 9/2008, adalah sebagai upaya memanfaatkan lebak, lebung, sungai, dan perairan rawa dalam wilayah OKI untuk kesejahteraan masyarakat. Maksud dan tujuan Perda OKI No. 9/2008 tersebut adalah mengatur tata cara pengelolaan serta pemanfaatan lebak, lebung, dan sungai wilayah kabupaten, adalah guna pemberdayaan ekonomi masyarakat desa dalam rangka penguatan otonomi desa dan peningkatan pendapatan asli desa.

Dijabarkan melalui Perda OKI No. 9/2008, dijabarkan lebih lanjut melalui Peraturan Bupati OKI No. 44 Tahun 2008, tentang Tata Cara Pengelolaan Lebak, Lebung, dan Sungai dalam Kabupaten Ogan Komering Ilir (PERBUP OKI No. 44/2008). PERBUP OKI No. 44/ 2008, kemudian ditindaklanjuti dengan Keputusan Bupati OKI No. 500/KEP/D.KP/ 2008, tentang Penetapan Lebak, Lebung, dan Sungai yang Dilelang dan Tidak Dilelang serta Harga Standar Lelang Lebak, Lebung, dan Sungai Tahun 2008, dengan masa pengelolaan terhitung mulai tanggal 1 Januari 2009 - 31 Desember 2009 dalam Kabupaten OKI. Kebijakan dan regulasi tersebut menyebabkan pengelolaan perairan umum daratan (PUD) di Sumsel, mengalami perubahan kelembagaan sebagai proses penyelarasan kebutuhan yang bersifat sosial.

Perubahan kelembagaan menurut Yustika (2006), berarti terjadinya perubahan di dalam prinsip regulasi, organisasi, perilaku, dan pola interaksi. Perubahan egulasi baru di dalam Perda OKI No. 9/ 2008 yang fundamental adalah tidak lagi dilelangnya lebak, lebung, dan sungai, melainkan dikembalikan kepada desa. Pelaksanaan ketentuan baru kelembagaan pemerintah desa dalam beberapa kondisi, tidak sesuai dengan sistem sosial yang berkembang di masyarakat. Pola perubahan kelembagaan dengan adanya Perda OKI No. 9/2008, justru memunculkan friksi antara kepentingan desa dengan keinginan masyarakat dalam mengelola dan memanfaatkannya.

Kurangnya pembelajaran dan pemahaman Pemerintah Kabupaten OKI terhadap karakteristik wilayah desa, memberikan kesan pemberlakuan Perda OKI No. 9/2008 terlalu dipaksakan. Sehubungan dengan paparan tersebut, tujuan dari penelitian ini untuk mengidentifikasi perubahan kelembagaan dalam pengelolaan PUD. Secara khusus, penelitian ini bertujuan menganalisis implementasi dan antisipasi dampak ketentuan baru Perda OKI No. 9/2008, yang menjadi kewenangan desa serta mengetahui proses pelaksanaannya.

\section{METODE PENELITIAN}

\section{Kerangka Pikir}

Hukum dapat berfungsi sebagai sarana pembaharuan di dalam masyarakat. Perda OKI No. 9/2008, telah memberikan aturan dan norma baru guna mewujudkan otonomi serta kelanjutan pembangunan desa. Ketentuan dan norma baru tersebut mengatur mengenai lebak, lebung, dan sungai yang tidak dilelang. Pengembalian manfaat ekonomi yang lebih besar kepada 
desa, membawa perubahan kelembagaan pengelolaan PUD. Kondisi ini terjadi karena adanya pergeseran nilai dan kultur masyarakat seiring dengan adanya perubahan waktu.

Menurut Scott (2008), kelembagaan mencakup regulasi, norma, dan elemen budaya kognitif, bersama-sama dengan kegiatan dan sumber daya yang ada, dalam upaya mewujudkan stabilitas serta memaknai sesuatu dalam kehidupan sosial. Yustika (2006), mengatakan bahwa perubahan kelembagaan dianggap mempunyai kekuatan aktif (besar) dalam mempengaruhi aspek kehidupan sosial, hukum, ekonomi, dan lainnya. Kedua pendapat tersebut memberikan pandangan, apabila norma yang mengatur interaksi sosial berubah maka seluruh pola hubungan sosial masyarakat dapat pula berubah.

\section{Keberadaan Perda OKI No. 9/2008 dan pembangunan kelembagaan, merupakan dasar seluruh proses sosial maupun pengelolaan sumber daya ikan PUD di Desa Berkat (Gambar 1). Perubahan kelembagaan dengan berlakunya Perda OKI No. 9/2008, memunculkan pengakuan}

hak atas kekayaan desa dan otonomi wilayah PUD. Transformasi kelembagaan dapat berperan, karena adanya ikatan sosial masyarakat berupa kepemilikan bersama dalam melakukan penangkapan ikan. Kondisi ini menimbulkan perubahan kebiasaan dan relasi sosial masyarakat dalam memanfaatkan PUD, sehingga memerlukan adanya upaya penyesuaian dalam menyikapinya.

\section{Pendekatan Penelitian}

$\begin{array}{ccc}\text { Penelitian dilakukan } & \text { dengan } \\ \text { menggunakan } & \text { pendekatan historis }\end{array}$ kasuistik, yaitu memahami pengelolaan PUD Sumsel masa sekarang atas dasar peristiwa masa lampau. Pemahaman pengelolaan PUD yang dikaji dalam penelitian ini, yaitu pada masa pemerintahan marga sampai 1982, pemerintahan kabupaten 1982 - 2008, dan pemerintahan kabupaten 2008 - 2010. Hasil kajian yang diperoleh dianalisis untuk memberikan gambaran sejarah pengelolaan PUD di Desa Berkat, serta perbandingan kebijakan yang berlaku pada masa yang berbeda.

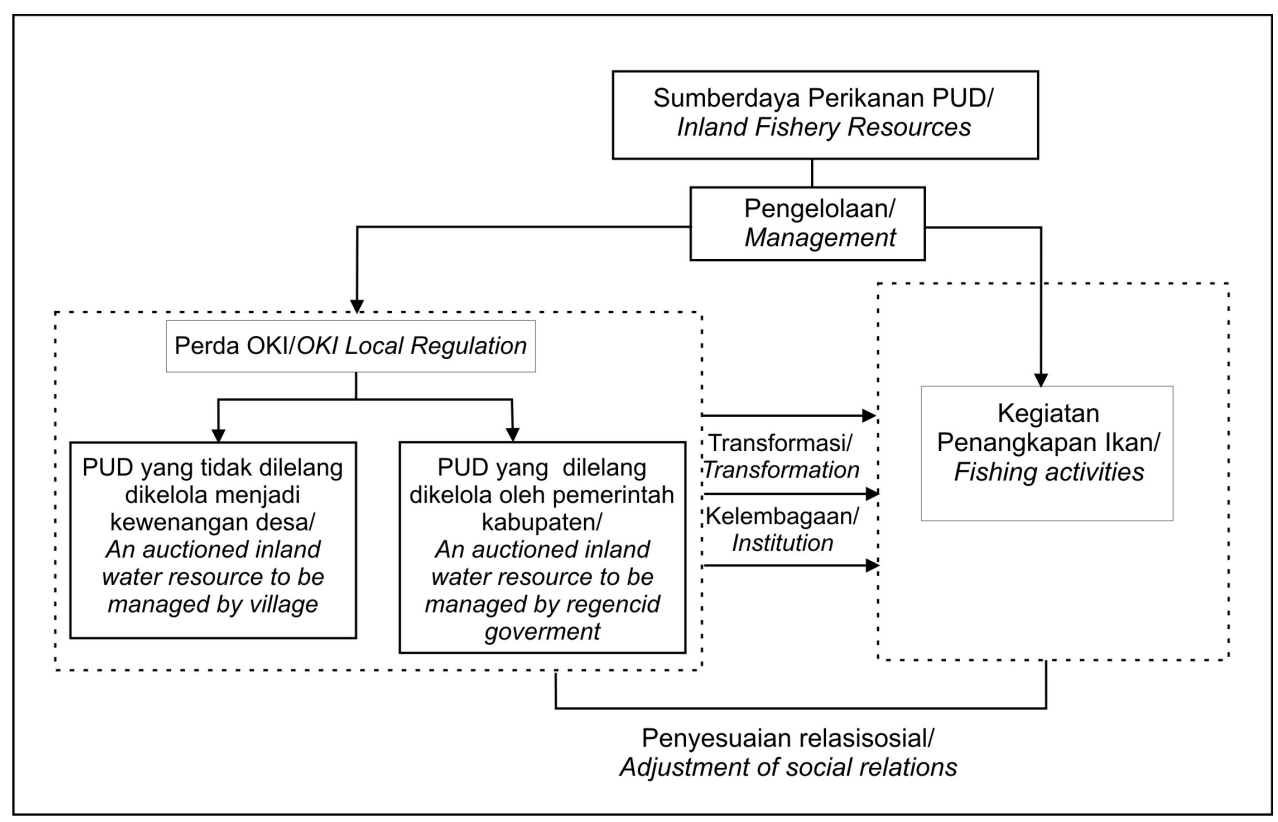

Gambar 1. Kerangka Berpikir Penelitian Perairan Umum Daratan di OKI, 2009

Figure 1. Logical Framework of the Inland Waters Research in OKI, 2009. 


\section{Lokasi dan Waktu}

Penelitian dilaksanakan pada bulan Juni 2009, di Desa Berkat, Kecamatan Sirah Pulau Padang, Kabupaten OKI, Provinsi Sumsel. Desa ini dipilih karena telah menginternalisasikan Perda OKI No. 9/2008.

\section{Metode Pengumpulan Data}

Data primer dikumpulkan melalui wawancara mendalam terhadap informan kunci (key person) aparatur Pemerintah Daerah OKI, masyarakat, dan aparatur pemerintah desa (kepala desa, sekretaris desa, dan aparat satuan keamanan) Berkat. Data sekunder yang dibutuhkan dikumpulkan melalui: UUD 1945; UU No. 32/2004 tentang Pemerintah Daerah, UU No. 31 Tahun 2004, tentang Perikanan sebagaimana telah diubah dengan UU No. 45 Tahun 2009, tentang Perubahan atas UU No. 31 Tahun 2004, tentang Perikanan; Perda OKI No. 9/2008 tentang Pengelolaan Lebak, Lebung, dan Sungai dalam Kabupaten Ogan Komering Ilir; Peraturan Bupati OKI No. 44/2008, tentang Tata Cara Pengelolaan Lebak, Lebung, dan Sungai dalam Kabupaten Ogan Komering Ilir; Keputusan Bupati OKI No. 500/KEP/D.KP/2008, tentang Penetapan Lebak, Lebung, dan Sungai yang Dilelang dan Tidak Dilelang serta Harga Standar Lelang Lebak, Lebung, dan Sungai Tahun 2008 Masa Pengelolaan Terhitung mulai Tanggal 1 Januari 2009 sampai dengan 31 Desember 2009 dalam Kabupaten OKI; hasil penelitian; serta literatur terkait.

\section{Metode Analisis Data}

Data yang diperoleh dianalisis menggunakan metode deskriptif eksploratif. Metode deskriptif eksploratif dipilih untuk menggambarkan perubahan kelembagaan dengan diberlakukannya Perda OKI No. 9/2008, yang berpedoman pada pelaksanaan tata pemerintahan desa di dalam mengelola dan memanfaatkan
PUD. Metode ini juga digunakan untuk mendapatkan pemahaman mengenai ketentuan baru PerdaOKI No. 9/2008, yang menjadi kewenangan desa dan fenomena pelaksanaannya.

\section{HASIL DAN PEMBAHASAN}

\section{Gambaran Umum Desa Berkat}

Karakteristik alam di lebak, lebung, dan sungai di Desa Berkat, pada saat musim hujan mengakibatkan lahan persawahan menjadi tenggelam karena air pasang. Pada musim ini, alam memberikan berkah berupa ikan berlimpah untuk dimanfaatkan masyarakat. Istilah pemanfaatan sumber daya ikan yang dilakukan masyarakat setempat, disebut dengan berkarang. Desa Berkat memiliki aliran anak Sungai Komering, yang mempunyai lebar kurang lebih 10 sampai 12 meter. Lokasi penangkapan ikan terletak di wilayah Lebak Belanti II, Ulak Muntate II, dan Lebak Muntate III. Efektivitas kegiatan penangkapan ikan pada ketiga wilayah tersebut, hanya dilakukan selama 2 - 5 bulan.

\section{Kelembagaan Perairan Umum Daratan}

Pemerintahan desa pada masa kolonial diatur di dalam Pasal 118 jo Pasal 121, Indische Staatsregeling (UUD Hindia Belanda). Pada Tahun 1938, melalui Inlandsche Gemeente Ordonantie voor Buitengewesten (IGOB), Staadblad No. 490, nama dan persekutuan masyarakat asli di bekas Keresidenan Palembang, disebut marga. Bentuk dan susunan pemerintahannya ditentukan berdasarkan hukum adat (Indische Staatsregeling dan IGOB, Staadblad No. 490 Tahun 1938 (Widjaja, 2002). Pada tahun 1965, pemerintah Orde Lama melakukan menyeragamkan istilah desa melalui penyusunan UU No. 19 Tahun 1965, tentang Desapraja sebagai Bentuk Peralihan untuk Mempercepat Terwujudnya Daerah Tingkat III di Seluruh Wilayah Republik Indonesia UU NO. 19 Tahun 1965 belum sempat dilaksanakan. 
Penyeragaman nama, bentuk, susunan, dan kedudukan pemerintahan desa, terlaksana melalui UU No. 5 Tahun 1979, tentang Pemerintahan Desa (UU No. 5/1979). Pemerintahan desa berdasarkan UU No. 5/1979, tidak memiliki hak pengaturan di bidang hak ulayat atau hak wilayah (Widjaja, 2002). Pengaturan pemerintahan desa kemudian diperbarui melalui UU No. 32 Tahun 2004, tentang Pemerintahan Daerah (UU No. 32/2004). Ketentuan pengaturan dan kepengurusan desa berdasarkan UU No. 32/2004, didasarkan kepada asal usul serta adat istiadat yang diakui sistem pemerintahan nasional di daerah kabupaten. Terminologi desa menurut UU No. 32/2004:

"kesatuan masyarakat hukum yang memiliki batas-batas wilayah yang berwenang untuk mengatur dan mengurus kepentingan masyarakat setempat, berdasarkan asal-usul dan adat istiadat setempat yang diakui dan dihormati dalam sistem Pemerintahan Negara Kesatuan Republik Indonesia".

Perubahan kelembagaan pada tiga masa pemerintahan, memunculkan mekanisme baru pengelolaan PUD di wilayah yang dilelang. Manig dalam Yustika (2006), mengatakan bahwa tujuan utama perubahan kelembagaan adalah untuk menginternalisasikan potensi produktivitas yang lebih besar. Menurut Yustika (2006), perubahan kelembagaan dianggap sebagai proses terus menerus yang bertujuan memperbaiki kualitas interaksi (ekonomi) antar pelakunya. Hak wilayah yang dilelang sebelum tahun 1982 diatur di dalam Perda Tingkat I, Provinsi Sumsel No. 8/Perdass/1973/1974 dan Perda Provinsi Sumsel No. 6 Tahun 1978, tentang Perubahan Pengaturan Lelang Lebak Lebung.

Pada tahun 1982, ketentuan lelang ditata ulang kembali dengan diterbitkannya Surat Keputusan (SK) Gubernur Sumsel No. 705/KPTS/II/1982 (SK GUB No. 705/ KPTS/II/1982). SK GUB No. 705/KPTS/II/1982.
Menurut Nasution et al. (2009), memberikan wewenang kepada pemerintah kabupaten untuk melaksanakan serta mengawasi lelang lebak dan lebung. Ketidaksesuaian pengaturan lelang berdasarkan SK GUB No. 705/KPTS/II/1982 dengan kondisi saat ini, menyebabkan Pemerintah Daerah OKI perlu untuk mengaturnya kembali melalui Perda OKI No. 9/2008. Dinamika pengelolaan PUD pada tiga masa pemerintahan, dapat dilihat pada Tabel 1.

Dinamika pengelolaan terkait diberlakukannya Perda OKI No. 9/2008 di dalam Tabel 1, menunjukkan adanya penataan kembali kegiatan pelelangan PUD di Desa Berkat. Pengaturan mengenai tata cara lelang yang digunakan dilakukan melalui sistem penawaran bertahap naik dan terbuka. Lelang dilaksanakan di muka umum dengan masa hak penguasaan wilayah lelang selama satu tahun (penawar tertinggi wajib membayar kontan dengan uang tunai). Apabila penawar tertinggi tidak melakukannya, maka pelelangan dianggap batal dan dilakukan pelelangan ulang.

Sistem pelelangan dilakukan dua kali dan bila tidak ada pemenangnya kembali, maka objek lelang tersebut dinyatakan tidak laku. Objek lelang yang tidak terjual pada lelang umum, akan ditawarkan kembali secara terbuka di kantor ibukota kabupaten untuk seluruh kecamatan (ditentukan bupati). Orang yang memberikan penawaran lelang tertinggi, serta mampu membayar harganya dan dinyatakan sebagai pemenang oleh panitia lelang, disebut pengemin. Pengemin mempunyai hak mengatur harga dan lamanya sewa objek, serta alat tangkap untuk mengambil ikan di wilayahnya.

Pemanfaatan uang hasil lelang sebesar $8 \%$ ditujukan untuk pembinaan teknis, perlindungan, dan pengawasan sumber daya ikan dirasakan tidak cukup nilainya. Menurut Nasution et al., (2009), nilai ini belum memadai apabila dibandingkan dengan besarnya uang hasil lelang yang diterima. 
Tabel 1. Dinamika Pengelolaan Perairan Umum Daratan di OKI 1982 - 2010. Table 1. Dinamics of Inland Waters Management in OKI 1982 - 2010.

\begin{tabular}{|c|c|c|c|}
\hline $\begin{array}{l}\text { Komponen } \\
\text { Perubahan/ } \\
\text { Component of } \\
\text { Change }\end{array}$ & $\begin{array}{l}\text { Pemerintah Marga/ } \\
\text { Clan Government } \\
\text { (sampai/until 1982) }\end{array}$ & $\begin{array}{l}\text { Pemerintah Kabupaten/ } \\
\text { Disrict Government } \\
(1982-2008)\end{array}$ & $\begin{array}{l}\text { Pemerintah Kabupaten/ } \\
\text { Distric Government } \\
(2008-2010)\end{array}$ \\
\hline $\begin{array}{l}\text { Penanggung jawab } \\
\text { lelang/Person } \\
\text { responsible for } \\
\text { auction }\end{array}$ & $\begin{array}{l}\text { Pasirah (kepala } \\
\text { pemerintah marga)/ } \\
\text { Pasirah (head of clan } \\
\text { government) }\end{array}$ & Bupati/Regent & $\begin{array}{l}\text { Bupati dan wakil bupati/ } \\
\text { Regent and vice regent }\end{array}$ \\
\hline $\begin{array}{l}\text { Pelaksana } \\
\text { pelelangan/ } \\
\text { Auctioneer }\end{array}$ & Pasirah/Pasirah & $\begin{array}{l}\text { Camat sebagai ketua } \\
\text { panitia pelaksana } \\
\text { pelelangan/Sub-district } \\
\text { executive as a committee } \\
\text { chairman auction }\end{array}$ & $\begin{array}{l}\text { Tingkat kabupaten oleh } \\
\text { Kepala Dinas Kelautan } \\
\text { dan Perikanan; tingkat } \\
\text { kecamatan oleh camat/ } \\
\text { District level by the Head } \\
\text { Office of Marine and } \\
\text { Fisheries; sub- district } \\
\text { level by sub-district head }\end{array}$ \\
\hline $\begin{array}{l}\text { Peserta lelang } \\
\text { yang berhak } \\
\text { mengadakan } \\
\text { penawaran/ } \\
\text { Bidders are } \\
\text { entitled to make } \\
\text { offer }\end{array}$ & $\begin{array}{l}\text { Masyarakat nelayan } \\
\text { yang bermukim di } \\
\text { dalam wilayah marga } \\
\text { setempat/Fishing } \\
\text { communities living in } \\
\text { the territory of the local } \\
\text { clan }\end{array}$ & $\begin{array}{l}\text { Dapat diikuti oleh } \\
\text { masyarakat bukan } \\
\text { nelayan (pedagang) } \\
\text { yang tidak bermukim } \\
\text { di wilayah kecamatan } \\
\text { setempat/ Can be } \\
\text { participated by the } \\
\text { society for fishermen } \\
\text { (traders) who do not } \\
\text { reside in the territory of } \\
\text { the local sub-district }\end{array}$ & $\begin{array}{l}\text { (a) Seluruh masyarakat } \\
\text { di wilayah kecamatan } \\
\text { yang berdomisili } \\
\text { minimal } 6 \text { bulan; (b) } \\
\text { Koperasi dengan bidang } \\
\text { usaha perikanan/(a) } \\
\text { The entire community } \\
\text { in the district who live } \\
\text { at least } 6 \text { months; } \\
\text { (b) Cooperation with } \\
\text { enterprises in the } \\
\text { fisheries }\end{array}$ \\
\hline $\begin{array}{l}\text { Penetapan objek } \\
\text { dan harga yang } \\
\text { dilelangkan/ } \\
\text { Determination of } \\
\text { the object and the } \\
\text { tendered price }\end{array}$ & $\begin{array}{l}\text { Objek lelang tidak } \\
\text { berubah setiap } \\
\text { tahunnya dan harga } \\
\text { ditetapkan oleh Pasirah } \\
\text { (tidak ada harga } \\
\text { standar perairan yang } \\
\text { akan dilelang)/The } \\
\text { object of the auction } \\
\text { does not change every } \\
\text { year and the price set } \\
\text { by Pasirah (there is no } \\
\text { standard price of water } \\
\text { that will be auctioned) }\end{array}$ & $\begin{array}{l}\text { Objek lelang } \\
\text { berubah setiap tahunnya } \\
\text { dan harga ditetapkan } \\
\text { oleh bupati/Object } \\
\text { auction changes every } \\
\text { year and the price set by } \\
\text { the regents }\end{array}$ & $\begin{array}{l}\text { Objek lelang tidak } \\
\text { berubah. Harga standar } \\
\text { ditetapkan oleh } \\
\text { bupati yang diajukan } \\
\text { kepada Kepala Dinas } \\
\text { Kelautan dan Perikanan } \\
\text { (mempertimbangkan } \\
\text { usul camat)/The object } \\
\text { of the auction does not } \\
\text { change. The standard } \\
\text { price set by the regents } \\
\text { which is submitted } \\
\text { by the Head Office of } \\
\text { Marine and Fisheries } \\
\text { Affairs (considering } \\
\text { proposals sub-district } \\
\text { head) }\end{array}$ \\
\hline
\end{tabular}




\begin{tabular}{|c|c|c|c|}
\hline $\begin{array}{l}\text { Komponen } \\
\text { Perubahan/ } \\
\text { Component of } \\
\text { Change }\end{array}$ & $\begin{array}{l}\text { Pemerintah Marga/ } \\
\text { Clan Government } \\
\text { (sampai/until 1982) }\end{array}$ & $\begin{array}{l}\text { Pemerintah Kabupaten/ } \\
\text { Disrict Government } \\
(1982-2008)\end{array}$ & $\begin{array}{l}\text { Pemerintah Kabupaten/ } \\
\text { Distric Government } \\
(2008-2010)\end{array}$ \\
\hline $\begin{array}{l}\text { Pemanfaatan } \\
\text { uang hasil lelang/ } \\
\text { Utilization of } \\
\text { the proceeds of } \\
\text { auction }\end{array}$ & $\begin{array}{l}\text { Menjadi pendapatan } \\
\text { marga yang memliki } \\
\text { perairan yang } \\
\text { dilelangkan dan } \\
\text { digunakan secara } \\
\text { otonom oleh } \\
\text { pemerintah marga yang } \\
\text { bersangkutan/Become } \\
\text { revenue clan who } \\
\text { possess the tendered } \\
\text { waters and used } \\
\text { autonomously by the } \\
\text { government concerned } \\
\text { clan }\end{array}$ & $\begin{array}{l}\text { Menjadi hak pemerintah } \\
\text { kabupaten dan } \\
\text { dikembalikan sebesar } \\
10 \% \text { untuk seluruh desa } \\
\text { di wilayah kabupaten } \\
\text { (meskipun desa tersebut } \\
\text { tidak mempunyai objek } \\
\text { perairan yang dapat } \\
\text { dilelangkan)/ Auction } \\
\text { results to the right of } \\
\text { local governments and } \\
\text { returned by } 10 \% \text { for all } \\
\text { villages in the district } \\
\text { (although the village } \\
\text { does not have an object } \\
\text { that can be tendered } \\
\text { waters) }\end{array}$ & $\begin{array}{l}50 \% \text { kas desa; } 33 \% \\
\text { untuk daerah; } 2 \% \\
\text { pengawas lelang; } 2 \% \\
\text { panitia pelaksana } \\
\text { kabupaten; } 2 \% \text { panitia } \\
\text { pelaksana kecamatan; } \\
3 \% \text { kepala desa; dan } 8 \\
\% \text { pembinaan teknis, } \\
\text { perlindungan, serta } \\
\text { pengawasan sumber } \\
\text { daya ikan/ } \\
50 \% \text { village treasury; } \\
33 \% \text { for the area; } 2 \% \\
\text { auction supervisor; } \\
2 \% \text { district executive } \\
\text { committee; } 2 \% \text { sub- } \\
\text { district executive } \\
\text { committee; } 3 \% \text { village } \\
\text { head; } 8 \% \text { technical } \\
\text { development, } \\
\text { protection, as well } \\
\text { as monitoring of fish } \\
\text { resources }\end{array}$ \\
\hline $\begin{array}{l}\text { Hak pemenang } \\
\text { lelang (pengemin } \\
\text { secara umum)/The } \\
\text { auction winner } \\
\text { (pengemin rights } \\
\text { in general) }\end{array}$ & $\begin{array}{l}\text { Masyarakat nelayan } \\
\text { yang bermukim di } \\
\text { dalam wilayah marga } \\
\text { setempat/Fishing } \\
\text { communities living in } \\
\text { the territory of the local } \\
\text { clan }\end{array}$ & $\begin{array}{l}\text { Dapat diikuti oleh } \\
\text { masyarakat bukan } \\
\text { nelayan (pedagang) } \\
\text { yang tidak bermukim } \\
\text { di wilayah kecamatan } \\
\text { setempat/ Can be } \\
\text { participated by the } \\
\text { society for fishermen } \\
\text { (traders) who do not } \\
\text { reside in the territory of } \\
\text { the local sub-district }\end{array}$ & $\begin{array}{l}\text { (a) Seluruh masyarakat } \\
\text { di wilayah kecamatan } \\
\text { yang berdomisili } \\
\text { minimal } 6 \text { bulan; } \\
\text { (b) Koperasi dengan } \\
\text { bidang usaha perikanan/ } \\
\text { (a)The entire community } \\
\text { in the district who live } \\
\text { at least } 6 \text { months; } \\
\text { (b) Cooperation with } \\
\text { enterprises in the } \\
\text { fisheries }\end{array}$ \\
\hline
\end{tabular}

Sumber: Nasution et al., 2009./Source: Nasution et al., 2009.

Perbaikan kelembagaan dengan adanya Perda OKI No. 9/2008, berdampak pada pemberdayaan ekonomi masyarakat dan Desa Berkat. Pemberdayaan ini diartikan, sebagai kegiatan terbuka dengan menggunakan pola pengembangan bersama yang bertanggung jawab.
Kegiatan pengelolaan yang terbuka, secara tidak langsung mempengaruhi tatanan relasi sosial terhadap pola kehidupan masyarakat Desa Berkat pada umumnya. Pengaruh ini terlihat melalui adanya perubahan relasi sosial antar masyarakat dan pedagang di masa pemerintahan 
marga, yang lebih mengutamakan hubungan perdagangan ikan. Pola relasi sosial yang terjadi pada masa itu, telah mempengaruhi dasar penetapan harga ikan. Perubahan juga terlihat pada masa setelah pemerintahan marga, yang menganggap status sosial pengemin tidak lagi lebih tinggi dan berjasa.

\section{Kewenangan Desa}

Berlakunya Perda OKI No. 9/2008, membuat akses masyarakat untuk memanfaatkan wilayah PUD menjadi semakin luas dan mudah. Berdasarkan hal tersebut, pembahasan kewenangan desa difokuskan untuk mengkaji aturan baru PERDA OKI
No. 9/2008, mengenai PUD yang tidak dilelang. Pengaturan kewenangan pengelolaan oleh Desa Berkat terhadap lebak, lebung, dan sungai yang tidak dilelang, dapat dilihat pada Tabel 2.

Berdasarkan Tabel 2, penetapan kriteria objek pengelolaan lebak, lebung, dan sungai yang tidak dilelang, tercantum pada Bab III, Pasal 3 perda No. 9/2008, dimana materinya mensyaratkan kepada desa untuk memiliki suaka perikanan. Menurut UU 31/2004tentangPerikanan, Pasal 7, Ayat (1), kawasan konservasi perairan sepert di Desa Berkat disebut sungai larangan) merupakan bentuk suaka perikanan.

Tabel 2. Kinerja Implementasi dan Dampak Pemanfaatan PerdaPerairan Umum Daratan di OKI, 2008.

Table 2. Implementation Performance and Utilization Impact of Inland Waters of Local Regulation in OKI, 2008.

\begin{tabular}{|c|c|c|c|}
\hline $\begin{array}{l}\text { Ketentuan/ } \\
\text { Conditions }\end{array}$ & $\begin{array}{l}\text { Perda OKI No. 9/2008/OKI } \\
\text { Local Regulation No. 9/2008 }\end{array}$ & $\begin{array}{l}\text { Implementasi/ } \\
\text { Implementation }\end{array}$ & $\begin{array}{l}\text { Dampak/ } \\
\text { Impact }\end{array}$ \\
\hline $\begin{array}{l}\text { Kriteria objek } \\
\text { pengelolaan/ } \\
\text { Criteria of } \\
\text { management } \\
\text { object }\end{array}$ & $\begin{array}{l}\text { Pasal 3/Article } 3 \\
\text { Petunjuk dan persyaratan } \\
\text { penetapan wilayah lebak, } \\
\text { lebung, dan sungai yang tidak } \\
\text { dilelang/Instructions and } \\
\text { requirements for zoning lebak, } \\
\text { lebung, and rivers that are not } \\
\text { auctioned }\end{array}$ & $\begin{array}{l}\text { Pemerintah Desa } \\
\text { Berkat menetapkan } \\
\text { batas lebak, lebung, } \\
\text { dan sungai yang } \\
\text { tidak dilelang, serta } \\
\text { konservasi perikanan/ } \\
\text { Berkat Village } \\
\text { Government sets limits } \\
\text { lebak, lebung, and } \\
\text { rivers that are not } \\
\text { auctioned areas, and } \\
\text { fisheries conservation }\end{array}$ & $\begin{array}{l}\text { Kewenangan } \\
\text { pemanfaatan lebak, } \\
\text { lebung, dan sungai } \\
\text { yang tidak dilelang, } \\
\text { dapat dikelola oleh } \\
\text { desa/Utilization } \\
\text { authority of lebak, } \\
\text { lebung, and rivers are } \\
\text { not auctioned, can be } \\
\text { managed by village }\end{array}$ \\
\hline $\begin{array}{l}\text { Pola } \\
\text { pengelolaan/ } \\
\text { Patterns of } \\
\text { management }\end{array}$ & $\begin{array}{l}\text { Pasal 4/Article 4 } \\
\text { Petunjuk pengelolaan serta } \\
\text { pelestarian sumber daya ikan di } \\
\text { lebak, lebung, dan sungai yang } \\
\text { tidak dilelang/Management } \\
\text { guidance and preservation } \\
\text { of fish resources in the lebak, } \\
\text { lebung, and rivers that are not } \\
\text { auctioned }\end{array}$ & $\begin{array}{l}\text { Pemerintah Desa Berkat } \\
\text { menetapkan jenis } \\
\text { sumber daya ikan yang } \\
\text { dilarang diambil oleh } \\
\text { masyarakat/Berkat } \\
\text { Village Government } \\
\text { decide the type of fish } \\
\text { resources is prohibited } \\
\text { taken by the community }\end{array}$ & $\begin{array}{l}\text { Keutuhan dan } \\
\text { kelestarian sumber } \\
\text { daya ikan di lebak, } \\
\text { lebung, dan sungai } \\
\text { yang tidak dilelang, } \\
\text { dapat terjaga dengan } \\
\text { baik/Integrity and } \\
\text { sustainability of fish } \\
\text { resources in the lebak, } \\
\text { lebung, and rivers that } \\
\text { are not auctioned, can } \\
\text { be better maintained }\end{array}$ \\
\hline
\end{tabular}


Tabel 3. Kinerja Implementasi dan Dampak Pemanfaatan Perda Perairan Umum Daratan di OKI, 2008.

Table 3. Implementation Performance and Utilization Impact of the Local Regulation on Inland Waters in OKI, 2008.

\begin{tabular}{|c|c|c|c|}
\hline $\begin{array}{l}\text { Ketentuan/ } \\
\text { Conditions }\end{array}$ & $\begin{array}{l}\text { PERDA OKI No. 9/2008/OKI } \\
\text { Local Regulation No. 9/2008 }\end{array}$ & $\begin{array}{l}\text { Implementasi/ } \\
\text { Implementation }\end{array}$ & $\begin{array}{c}\text { Dampak/ } \\
\text { Impact }\end{array}$ \\
\hline $\begin{array}{l}\text { Tata cara } \\
\text { pemanfaatan } \\
\text { sumber } \\
\text { daya ikan/ } \\
\text { Procedur of } \\
\text { fish resources } \\
\text { Utilization }\end{array}$ & $\begin{array}{l}\text { Pasal 5/Article } 5 \\
\text { Petunjuk tata cara kegiatan } \\
\text { penangkapan ikan di lebak, } \\
\text { lebung dan sungai yang } \\
\text { tidak dilelang/Instructions } \\
\text { ordinances fishing activities } \\
\text { in the lebak, lebung, and } \\
\text { rivers that are not auctioned }\end{array}$ & $\begin{array}{l}\text { Pemerintah Desa Berkat } \\
\text { mewajibkan setiap orang } \\
\text { yang ingin menangkapikan, } \\
\text { melaporkan dan } \\
\text { mencatatkan kegiatannya } \\
\text { kepada aparat desa/Berkat } \\
\text { Village Government requires } \\
\text { every person who wants } \\
\text { to catch fish, report and } \\
\text { record its activities to village } \\
\text { officials }\end{array}$ & $\begin{array}{l}\text { Ketertiban kegiatan } \\
\text { menangkap ikan di } \\
\text { lebak, lebung, dan } \\
\text { sungai yang tidak } \\
\text { dilelang, dapat } \\
\text { terjamin/Order } \\
\text { fishing activities in } \\
\text { the lebak, lebung, } \\
\text { and rivers that are } \\
\text { not auctioned, can } \\
\text { be guaranteed }\end{array}$ \\
\hline
\end{tabular}

Sumber: PerdaOKI No. 9/2008./Source: OKI Local Regulation No. 9/2008.

Konservasi perairan adalah kawasan yang dilindungi serta dikelola dengan sistem zonasi, untuk mewujudkan pengelolaan sumber daya ikan dan lingkungannya secara berkelanjutan.

Materi Perda OKI No. 9/2008 yang mengatur kewenangan pengelolaan serta pemanfaatan lebak, lebung, dan sungai yang tidak dilelang, diatur di dalam Pasal 4. Pasal ini mewajibkan peraturan desa memuat tata cara pengelolaan, pemanfaatan, dan pelestarian ikan (melalui persetujuan Badan Permusyawaratan Desa). Ketentuan Perda OKI No. 9/2008, yang mengatur mengenai kewenangan pemanfaatan sumber daya ikan di lebak, lebung, dan sungai yang tidak dilelang, dapat dilihat pada Tabel 3.

Tata cata pemanfaatan sumber daya ikan menurut Pasal 5 Perda OKI No. 9/ 2008 pada Tabel 3, mewajibkan masyarakat mendaftarkan diri kepada aparat desa untuk memperoleh Surat Keterangan Pencatatan Penangkapan Ikan. Ketentuan Perda OKI No. 9/2008, yang mengatur kewenangan pembinaan dan pengawasan dalam rangka menjaga kepentingan bersama terhadap lebak, lebung, dan sungai yang tidak dilelang, dapat dilihat di dalam Tabel 4.

Soekanto (2008), menyatakan bahwa di dalam warga pasti ada warga atau pihak tertentu yang tidak mematuhi hukum. Penyelewengan tersebut harus ditanggulangi, artinya harus dicegah dan kalau sudah terjadi harus diatasi (preventif dan represi). Upaya menjaga kepentingan bersama menurut Pasal 7 Perda OKI No. 9/ 2008 dalam Tabel 4, merupakan kegiatan pembinaan dan pengawasan yang dilakukan Pemerintah Desa Berkat, Pemerintah Daerah OKI, dan kelompok pengawas masyarakat (Pokwasmas).

Pelaksanaan dan penerapan ketentuan Pasal 8 Perda OKI No. 9/ 2008, membutuhkan adanya kerja sama yang sinergis antara pihak terkait guna menghindari terjadinya pelanggaran. Ketentuan perlindungan dan pengawasan sumber daya ikan di dalam Perda OKI No. 9/2008, tidak secara tegas mengatur lebak, lebung, dan sungai yang tidak dilelang, namun materi pasalnya dapat dijadikan tinjauan yuridis dalam pelaksanaannya (Tabel 5). 


\section{Tabel 4. Kinerja Implementasi dan Dampak Pemanfaatan Perda Perairan Umum Daratan di OKI, 2008.}

Table 4. Implementation Performance and Utilization Impact of Inland Waters of Local Regulation in OKI, 2008.

\begin{tabular}{|c|c|c|c|}
\hline $\begin{array}{c}\text { Ketentuan/ } \\
\text { Conditions }\end{array}$ & Perda OKI No. 9/2008 & $\begin{array}{l}\text { Implementasi/ } \\
\text { Implementation }\end{array}$ & $\begin{array}{l}\text { Dampak/ } \\
\text { Impact }\end{array}$ \\
\hline $\begin{array}{l}\text { Pembinaan dan } \\
\text { pengawasan/ } \\
\text { Development and } \\
\text { supervision }\end{array}$ & $\begin{array}{l}\text { Pasal 7/Article 7 } \\
\text { Petunjuk pembinaan dan } \\
\text { pengawasan dalam menjaga } \\
\text { kepentingan bersama di lebak, } \\
\text { lebung, dan sungai yang tidak } \\
\text { dilelang/Directive guidance } \\
\text { and supervision in maintaining } \\
\text { common interests in the lebak, } \\
\text { lebung, and rivers that are not } \\
\text { auctioned }\end{array}$ & $\begin{array}{l}\text { Pemerintah Desa Berkat } \\
\text { membentuk satuan } \\
\text { keamanan desa sebelum } \\
\text { adanya Kelompok Pengawas } \\
\text { Masyarakat (POKWASMAS)/ } \\
\text { Berkat Village Government } \\
\text { form a village security force } \\
\text { before the Kelompok Pengawas } \\
\text { Masyarakat (POKWASMAS) }\end{array}$ & $\begin{array}{l}\text { Keberlanjutan sumber } \\
\text { daya ikan di lebak, } \\
\text { lebung, dan sungai } \\
\text { yang tidak dilelang, } \\
\text { dapat terjaga dengan } \\
\text { baik/The sustainability } \\
\text { of fish resources in } \\
\text { the lebak, lebung, and } \\
\text { rivers that are not } \\
\text { auctioned can be better } \\
\text { maintained }\end{array}$ \\
\hline $\begin{array}{l}\text { Bentuk } \\
\text { pembinaan dan } \\
\text { pengawasan/ } \\
\text { Form of } \\
\text { development and } \\
\text { supervision }\end{array}$ & $\begin{array}{l}\text { Pasal 8/Article } 8 \\
\text { Petunjuk pembinaan dan } \\
\text { pengawasan yang dilakukan } \\
\text { oleh pemerintah desa/ } \\
\text { Directive guidance and } \\
\text { supervision carried out by } \\
\text { village government }\end{array}$ & $\begin{array}{l}\text { Pemerintah Desa Berkat } \\
\text { menempatkan satuan } \\
\text { keamanan desa untuk ikut } \\
\text { melakukan pembinaan dan } \\
\text { pengawasan di wilayah lebak, } \\
\text { lebung, dan sungai yang } \\
\text { tidak dilelang/Berkat Village } \\
\text { Government puts the village } \\
\text { security forces to join do } \\
\text { coaching and supervision in } \\
\text { lebak, lebung, and rivers that } \\
\text { are not auctioned }\end{array}$ & $\begin{array}{l}\text { Tindakan sewenang- } \\
\text { wenang dan } \\
\text { pelanggaran dalam } \\
\text { pengelolaan di lebak, } \\
\text { lebung, dan sungai } \\
\text { yang tidak dilelang, } \\
\text { dapat dihindari/ } \\
\text { Arbitrary actions } \\
\text { and abuses in the } \\
\text { management of the } \\
\text { lebak, lebung, and } \\
\text { rivers that are not } \\
\text { auctioned, can be avoid }\end{array}$ \\
\hline
\end{tabular}

Sumber: Perda OKI No. 9/2008./Source: OKI Local Regulation No. 9/2008.

Pasal 22 Perda OKI No. 9/2008 (Tabel 5), menegaskan bahwa Pemerintah Daerah OKI mempunyai kewenangan tertinggi melakukan pembinaan, pengawasan, pengendalian dan perlindungan ikan, serta lingkungannya. Ketentuan perlindungan serta pengawasan dapat disimpangi untuk kepentingan riset dan ilmu pengetahuan, yang dituangkan di dalam naskah kesepakatan. Ketentuan Perda OKI No. 9/2008, yang mengatur mengenai larangan dan sanksi, (Tabel 6).

Pasal 23, 24, dan 32, Perda OKI No. $9 /$ 2008 (Tabel 6), meskipun tidak secara langsung terkait dengan lebak, lebung, dan sungai yang tidak dilelang, isi materi pasalnya dapat dijadikan pedoman untuk mengaturnya. Menurut Hoebel (2006), hukum berfungsi menjelaskan hubungan antara anggota masyarakat dan aktivitas yang boleh, serta dilarang oleh hukum. Khusus mengenai materi ketentuan larangan dan sanksi, PerdaOKI No. 9/2008 memberi kewenangan penuh kepada Pemerintah Desa Berkat untuk mengaturnya menurut kebutuhan desa. Maksud adanya petunjuk larangan dan sanksi agar dalam pengelolaan lebak, lebung, dan sungai yang tidak dilelang dapat dilaksanakan dengan tertib, serta hasilnya dapat dirasakan oleh desa dan masyarakat.

\section{Pelaksanaan PERDA OKI No. 9/2008}

\section{Pemanfaatan Sumber Daya Ikan}

Soekanto (2008), memandang hukum sebagai sarana untuk menciptakan keadaan tertentu, dan berperan sebagai sarana untuk mengadakan perubahan 
atau pembangunan. Pendapat tersebut menegaskan, bahwa penguasaan atau pengarahan proses sosial dengan diberlakukannya Perda OKI No. 9/2008, disebut (social engineering). Menurut Podgorecki dalam Abdurrahman (2009), asas di dalam usaha social engineering: (1) penggambaran situasi yang dihadapi dengan baik, (2) analisa terhadap penilaian, (3) verifikasi hipotesa, dan (4) pengukuran efek peraturan. Asas inilah yang tidak diperhatikan Pemerintah Daerah OKI saat menerapkan Perda OKI No. 9/2008 di Desa Berkat.

Ranah persoalan tentang hukum sekarang ini tidak lagi merupakan legalitas formal, penafsiran, dan penerapan pasal peraturan secara semestinya. Persoalan hukum telah bergerak ke arah penggunaan hukum sebagai sarana untuk membentuk

\section{Tabel 5. Kinerja Implementasi dan Dampak Pemanfaatan Perda Perairan Umum Daratan di OKI, 2008.}

Table 5. Implementation Performance and Utilization Impact of Inland Waters Local Regulation in OKI, 2008.

\begin{tabular}{|c|c|c|c|}
\hline $\begin{array}{c}\text { Ketentuan/ } \\
\text { Conditions }\end{array}$ & Perda OKI No. 9/2008 & $\begin{array}{l}\text { Implementasi/ } \\
\text { Implementation }\end{array}$ & $\begin{array}{l}\text { Dampak/ } \\
\text { Impact }\end{array}$ \\
\hline $\begin{array}{l}\text { Perlindungan } \\
\text { dan pengawasan } \\
\text { sumber daya } \\
\text { ikan/Protection } \\
\text { and surveillance } \\
\text { of fish resources }\end{array}$ & $\begin{array}{l}\text { Pasal 22/Article } 22 \\
\text { Petunjuk pelestarian } \\
\text { sumber daya ikan dan } \\
\text { lingkungan di wilayah } \\
\text { lebak, lebung, dan sungai/ } \\
\text { Hint conservation of } \\
\text { fish resources and the } \\
\text { environment in the lebak, } \\
\text { lebung, and river }\end{array}$ & $\begin{array}{l}\text { Pemerintah Desa Berkat melakukan } \\
\text { pengendalian dan perlindungan } \\
\text { sumber daya ikan, serta } \\
\text { lingkungannya dengan menetapkan } \\
\text { ketentuan ketentuan: } \\
\text { 1. Menangkap ikan yang akan dan/ } \\
\text { atau sedang bertelur; } \\
\text { 2. Menggunakan empang yang } \\
\text { memotong badan sungai yang } \\
\text { tidak dilelang; } \\
\text { 3. Menangkap anak-anak ikan dalam } \\
\text { masa pertumbuhan menjelang } \\
\text { dewasa/besar, dan ketika air mulai } \\
\text { naik (awal bulan Januari - } \\
\text { akhir bulan Maret); } \\
\text { 4. Mengidentifikasi jenis alat } \\
\text { penangkapan ikan yang } \\
\text { diperbolehkan untuk digunakan } \\
\text { masyarakat; } \\
\text { 5. Menangkap, mengangkut, dan } \\
\text { memperdagangkan anakan ikan/ } \\
\text { Berkat Village Government do } \\
\text { control and protection of fish } \\
\text { resources, and environment by } \\
\text { establishing provisions: } \\
\text { 1. Prohibiting fishing and/or are } \\
\text { laying eggs; } \\
\text { 2. Prohibiting use of cutting pond the } \\
\text { river that are not auctioned; } \\
\text { 3. Prohibiting capture little fish in the } \\
\text { growth towards the adult large, } \\
\text { and when water starts to rise (early } \\
\text { January - end of month March); } \\
\text { 4. Identify types of fishing gear are } \\
\text { allowed to use community } \\
\text { 5. Prohibiting capture, transport and } \\
\text { trade fry }\end{array}$ & $\begin{array}{l}\text { Kelestarian sumber } \\
\text { daya ikan di kawasan } \\
\text { lebak, lebung, } \\
\text { dan sungai yang } \\
\text { tidak dilelang, } \\
\text { dapat terjamin/ } \\
\text { Sustainability of fish } \\
\text { resources in the area } \\
\text { of lebak, lebung, and } \\
\text { rivers that are not } \\
\text { auctioned, can be } \\
\text { guaranteed }\end{array}$ \\
\hline
\end{tabular}

Sumber: Perda OKI No. 9/2008./Source: OKI Local Regulation No. 9/2008. 
tata kehidupan baru sesuai dengan kondisi saat ini. Akibat hukum diberlakukannya PerdaOKI No. 9/2008, menimbulkan adanya perubahan kebiasaan di Desa Berkat. Perubahan yang terjadi, diketahui dengan besarnya akses masyarakat untuk memanfaatkan sumber daya ikan di lebak dan lebung, dibandingkan peraturan sebelumnya.

Pemanfaatan yang dilakukan masyarakat Desa Berkat, pada kenyataannya belum memperhatikan ketentuan Perda OKI No. 9/2008. Masyarakat masih ada yang menggunakan alat tangkap yang dilarang, menangkap ikan kecil dalam masa pertumbuhan, dan menangkap ikan yang akan bertelur ${ }^{1}$. Lambatnya penanganan terhadap setiap pelanggaran yang terjadi, dikarenakan adanya anggapan bahwa untuk melakukan tindakan hukum harus terlebih dahulu mempunyai peraturan desa ${ }^{2}$.

\section{Pengaturan Alat Tangkap}

Merujuk kepada Perda OKI No. 9/2008, dalam upaya menjaga populasi sumber daya ikan di wilayah lebak, lebung, dan sungai yang tidak dilelang, Pemerintah Desa Berkat mengatur jenis alat tangkap yang dilarang dan tidak dilarang. Jenis alat tangkap yang dilarang dan masih digunakan oleh masyarakat Desa Berkat, yaitu tuguk (dioperasikan secara menetap) $)^{3}$. Tabel 6 Implementasi dan Dampak Implementasi Perda Perairan Umum Daratan di
OKI, 2008.

Table 6. Implementation of Local Regulation of its Inland Waters at OKI, 2008.

\begin{tabular}{|c|c|c|c|}
\hline $\begin{array}{c}\text { Ketentuan/ } \\
\text { Conditions }\end{array}$ & PERDA OKI No. 9/2008 & $\begin{array}{l}\text { Implementasi/ } \\
\text { Implementation }\end{array}$ & $\begin{array}{l}\text { Dampak/ } \\
\text { Impact }\end{array}$ \\
\hline $\begin{array}{l}\text { Larangan/ } \\
\text { Prohibition }\end{array}$ & $\begin{array}{l}\text { Pasal } 23 \text { dan Pasal } 24 / \\
\text { Article } 23 \text { and Article } 24 \\
\text { Petunjuk larangan di dalam } \\
\text { mengelola sumber daya ikan di } \\
\text { lebak, lebung, dan sungai secara } \\
\text { umum/Hint ban on managing } \\
\text { fish resources in the lebak, } \\
\text { lebung, and rivers in general }\end{array}$ & $\begin{array}{l}\text { Pemerintah Desa Berkat } \\
\text { menentukan kriteria bentuk } \\
\text { kegiatan yang dilarang } \\
\text { untuk dilakukan dalam } \\
\text { memanfaatkan sumber } \\
\text { daya ikan di wilayah lebak, } \\
\text { lebung, dan sungai yang } \\
\text { tidak dilelang/Berkat Village } \\
\text { Government determine the } \\
\text { criteria of activities that } \\
\text { are prohibited to be done } \\
\text { in exploiting fish resources } \\
\text { the lebak, lebung, and rivers } \\
\text { that are not auctioned }\end{array}$ & $\begin{array}{l}\text { Ketertiban pelaksanaan } \\
\text { kegiatan penangkapan } \\
\text { ikan di lebak, lebung, } \\
\text { dan sungai yang tidak } \\
\text { dilelang, dapat terjamin/ } \\
\text { Order fishing activities } \\
\text { in the lebak, lebung, } \\
\text { and rivers that are } \\
\text { not auctioned, can be } \\
\text { guaranteed }\end{array}$ \\
\hline $\begin{array}{l}\text { Sanksi/ } \\
\text { Sanction }\end{array}$ & $\begin{array}{l}\text { Pasal 32/Article } 32 \\
\text { Petunjuk pelaksanaan hukuman } \\
\text { terhadap pelaku tertentu yang } \\
\text { telah dianggap melakukan } \\
\text { pelanggaran LHint execution of } \\
\text { certain actors that have been } \\
\text { deemed in violation }\end{array}$ & $\begin{array}{l}\text { Penerapan sanksi yang } \\
\text { diberlakukan oleh } \\
\text { Pemerintah Desa Berkat, } \\
\text { meliputi pidana dan } \\
\text { perdata/Application of } \\
\text { sanctions imposed by the } \\
\text { Berkat Village government, } \\
\text { including criminal and civil }\end{array}$ & $\begin{array}{l}\text { Tindakan pelanggaran } \\
\text { hukum dalam } \\
\text { pemanfaatan lebak, } \\
\text { lebung, dan sungai yang } \\
\text { tidak dilelang dapat } \\
\text { dicegah/Unlawful acts } \\
\text { in the use of lebak, } \\
\text { lebung, and rivers that } \\
\text { are not auctioned, can be } \\
\text { prevented }\end{array}$ \\
\hline
\end{tabular}

Sumber: Perda OKI No. 9/2008./Source: OKI Local Regulation No. 9/2008.

\footnotetext{
${ }^{1}$ Hasil wawancara dengan petugas satuan keamanan Desa Berkat (19 Juni 2009).

${ }^{2}$ Hasil wawancara dengan dengan Kepala Desa Berkat (17 Juni 2009).

${ }^{3}$ Hasil wawancara dengan petugas satuan keamanan Desa Berkat (19 Juni 2009).
} 
Tuguk merupakan alat penangkapan ikan yang berbentuk jaring berkantong dan dioperasionalkan dengan metode menghadang ruaya (migrasi) ikan di sungai. Alat tangkap ini dilarang karena dapat mengganggu, menghambat, dan membahayakan lalu lintas perairan ${ }^{4}$.

Menurut Husnah et al. (2006), tuguk baris/awangan digunakan untuk menangkap Udang (Macrobrachium spp), sedangkan tuguk bilis/layangan digunakan untuk menangkap ikan Bilis (Rasbora spp) dan Julung-julung (Zenarchopterus spp). Cara penangkapan ikan yang juga dilarang adalah dengan menggunakan bahan kimia, bahan biologi, bahan peledak, dan aliran listrik setrum. Jenis alat tangkap yang tidak dilarang oleh Pemerintah Desa Berkat untuk digunakan di wilayah lebak, lebung, dan sungai yang tidak dilelang, dapat dilihat pada Tabel 7 .

\section{Tabel 7. Jenis Alat Tangkap dan Ikan Tangkapan yang Diizinkan pada Perairan Umum Daratan di OKI, 2006.}

Table 7. Type of Permitted Fishing Gear and Fish Caught in Inland Waters in OKI, 2006.

\begin{tabular}{cc}
\hline $\begin{array}{c}\text { Alat Tangkap/ } \\
\text { Fishing Gear }\end{array}$ Ikan Tangkapan/Fish Catch \\
\hline
\end{tabular}

Jala/Cast net

Jaring insang/

Gillnets

Pengilar/Traps

Bubu/Traps

\section{Seruo/Small traps}

Pancing dan rawai/Fishing rod and hook and line

Tangkul/Liftnet
Lumajang (Chyclocheilichthys enoplos), Siumbut Labiobarbus ocellatus), Sepatung (Pristolepis grootii), Are manis (Osteochilus schlegeli), Kojam (Labiobarbus spp), Udang (Macrobrachium spp), Lampam (Barbodes schwanenfeldii), Kepa (Puntioplites spp), Palau (Osteochilus hasseltii), Sihitam (Labeo chrysophekadion), Berengit (Mystus nigriceps)

\section{Sepat siam (Trychogaster pectoralis), Sepat merah mato (Trychogaster} trichopterus), Sapil (Helostoma spp), dan Betok (Anabas testudineus)

Jentulu (Barbichthys laevis), Palau (Osteochilus hasseltii), Lampam (Barbodes schwanenfeldii), Seluang (Rasbora spp), Udang (Macrobrachium spp), Gabus (Channa striata), Sepat siam (Trychogaster pectoralis), Tembakang (Helostoma temminckii), Sapil (Helostoma spp), Selincah (B. hasselti), Betok (Anabas testudineus)

Baung (Mystus nemurus), Sihitam (Labeo chrysophekadion), Berengit (Mystusnigriceps), Sepengkah (Parambasi wolffii), Kepras (Puntioplites waandersi), Kojam (Labiobarbus spp), Seluang (Rasbora spp), Layang (barbichthys spp), Udang (Macrobrachium spp), Belut (Monopterus spp)

\section{Seluang (Rasbora spp)}

Udang (Macrobrachium spp), Juara (Pangasius polyuranodon), Patin (Pangasius pangasius), Bulu ayam (Coilia lindmani), Sepat siam (Trychogaster pectoralis), Lele (Clarias spp), Betok (Anabas testudineus), Gabus (Channa striata), Lais (Kryptopterus schilbeides), Seluang (Rasbora spp), Baung (Mystus nemurus), Lampam (Barbodes schwanenfeldii), Tilan (Mastecembelus spp), Layang (Barbichthys spp)

Seluang (Rasbora spp), Lambak (Thycnichthys polylepis), Riu-riu (Pseudeutropius brachypopterus)

Sumber: Husnah et al., 2006./Source: Husnah et al., 2006.

${ }^{4}$ Hasil wawancara dengan Kepala Desa Berkat (19 Juni 2009). 


\section{Sosialisasi}

Montesquieu (2007), menyatakan bahwa hukum haruslah ringkas dan mudah dimengerti, sehingga ia akan berarti bagi siapapun yang membacanya. Cakupan materi Perda OKI No. 9/2008, merupakan rangkaian bahasa yang membutuhkan pendalaman lebih untuk dimengerti maksudnya. Hal ini menuntut adanya keseriusan proses sosialisasi secara holistik, agar rumusan pasalnya bisa dipahami dan dilaksanakan dengan baik oleh desa. Menurut Abdurrahman (2009), proses sosialisasi hukum sangat diperlukan agar masyarakat berperilaku sebagaimana yang diharapkan oleh hukum. Sosialisasi Perda OKI No. 9/2008, pada pelaksanaannya tidak tersampaikan dengan baik kepada Pemerintah Desa Berkat.

Kendala ini dikarenakan kurangnya sumber daya manusia (SDM) yang terampil hukum di Desa Berkat dalam memahami materi pasalnya 5 . Menurut Soekanto dalam Abdurrahman (2009), derajat tinggi rendahnya kepatuhan terhadap hukum positif tertulis, salah satunya didasarkan pengetahuan dan pemahaman hukum. Pengenalan rancangan peraturan desa oleh Kepala Desa Berkat, ternyata kurang mendapat respon yang baik juga oleh sebagian masyarakat. Kondisi tersebut, disebabkan masyarakat kurang memahami dengan baik tujuan peraturan desa yang disampaikan. Masyarakat beranggapan, bahwa pemberlakuan peraturan desa hanya diperuntukkan bagi kepentingan Kepala Desa dan sekelompok orang tertentu saja ${ }^{6}$.

Tidak adanya aparatur Pemerintah Kabupaten OKI yang membantu atau mendampingi menjelaskan kepada masyarakat, membuat rancangan peraturan desa Berkat tidak terinformasikan dengan baik ${ }^{7}$. Menanggapi hal tersebut, Pemerintah Daerah OKI menyatakan bahwa proses sosialisasi yang mereka lakukan sudah sesuai dengan yang diharapkan ${ }^{8}$. Kenyataan ini membuktikan, bahwa koordinasi antara Pemerintah Daerah OKI dengan Pemerintah Desa Berkat tidak berjalan dengan baik. Pelaksanaan sosialisasi yang kurang baik, menyebabkan hanya beberapa desa saja di Kabupaten OKI yang sudah memberikan rancangan peraturan desa untuk disetujui, termasuk salah satunya Desa Berkat.

\section{Komunikasi Hukum}

Faktor interval waktu yang terlalu lama sejak diberlakukannya Perda OKI NO. 9/2008, dengan pengajuan rancangan peraturan desa Berkat, seakan-akan tidak disadari sebagai suatu hambatan. Situasi ini menggambarkan, bahwa Pemerintah Daerah OKI tidak menggunakan fungsinya melalui komunikasi hukum untuk mengatasinya. Menurut Friedman (2009), komunikasi hukum merupakan persyaratan pokok sistem hukum. Tidak ada seorangpun dapat berperilaku menurut hukum, kalau ia tidak mengetahui apa isi atau apa yang diatur oleh hukum itu.

Pembuatan peraturan desa oleh Pemerintah Desa Berkat, pada kenyataannya kurang mendapat pengontrolan oleh Pemerintah Daerah $\mathrm{OKI}^{9}$. Kontrol ini diperlukan guna mengetahui hambatan yang dialami Pemerintah Desa Berkat dalam melaksanakan Perda OKI No. 9/2008. Kesan yang ditimbulkan, bahwa komunikasi hukum yang dilakukan Pemerintah Daerah OKI hanya untuk memenuhi syarat formal saja, yaitu dengan dimuatnya dalam Lembaran Daerah.

\footnotetext{
${ }^{5}$ Hasil wawancara dengan aparatur Pemerintah Daerah OKI (17 Juni 2009).

${ }^{6} \mathrm{Hasil}$ wawancara dengan masyarakat Desa Berkat (19 Juni 2009).

${ }^{7}$ Hasil wawancara dengan Kepala Desa Berkat (19 Juni 2009).

${ }^{8}$ Hasil wawancara dengan aparatur Pemerintah Daerah OKI (17 Juni 2009).

${ }^{9}$ Hasil wawancara dengan Kepala Desa Berkat (17 Juni 2009).
} 


\section{Penetapan Batas Desa}

F. C. von Savigny dalam Samidjo (1986), mengemukakan bahwa hukum tidak dapat dibuat, terkecuali terjadi atau diproses bersama-sama dengan masyarakat. Penentuan batas desa yang ditetapkan Pemerintah Kabupaten OKI, memiliki perbedaan berdasarkan pemahaman masyarakat dan Pemerintah Desa Berkat $^{10}$. Situasi ini menunjukkan, bahwa Pemerintah Daerah OKI tidak mengikutsertakan dan memahami peranan masyarakat sebagai salah satu faktor pembentukan hukum. Batas antar desa tetangga hanya diketahui dengan adanya pohon yang sudah tumbuh sejak dahulu, dan diyakini masyarakat sebagai penanda wilayah Desa Berkat ${ }^{11}$.

Adanya perbedaan mengenai batas wilayah desa, menimbulkan ketidakpastian dan rasa tidak percaya terhadap kredibilitas produk hukum yang dibuat oleh pembuat kebijakan. Menurut Sulistyowati Iriyanto dalam Cahyadi dan Danardono (2009), kenyataan ini memperlihatkan kegagalan pembangunan hukum. Kegagalan ini dikarenakan, Pemerintah Kabupaten OKI tidak memberikan ruang kepada masyarakat untuk memberikan suaranya dalam perancangan skema keadilan Pengembangan desa dewasa ini tidak bisa hanya mengandalkan aset desa saja, faktor lain yang lebih penting adalah memberdayakan SDM sebagai pengelola desa bersama masyarakat.

\section{Penegakan Hukum di Desa Berkat}

Sebelum adanya peraturan desa sebagai hukum positif tertulis, Pemerintah Desa Berkat menjadikan Perda OKI No. 9/2008 sebagai panduan pengelolaan serta pemanfaatan lebak, lebung, dan sungai yang tidak dilelang ${ }^{12}$. Keinginan Pemerintah
Desa Berkat melaksanakan Perda OKI No. 9/2008, kurang mendapatkan perhatian masyarakat karena pengaturannya masih bersifat umum dan kurang teknis ${ }^{13}$. Masyarakat Kabupaten OKI merasa dengan berlakunya Perda OKI No. 9/2008, mereka memiliki hak untuk memanfaatkan lebak, lebung, dan sungai di wilayahnya maupun di wilayah desa lain.

Kondisi ini menyebabkan pemanfaatan lebak, lebung, dan sungai di Desa Berkat, dilakukan juga oleh masyarakat luar desa. Keberadaan masyarakat luar desa, telah menimbulkan adanya kasus kehilangan kapal dan alat tangkap. Kejadian itu memunculkan konflik dengan masyarakat yang berada di luar Desa Berkat ${ }^{14}$. Faktor yang membuat kinerja satuan keamanan belum maksimal, karena tidak ada aparat penegak hukum yang mendampingi, serta tidak seimbangnya jumlah petugas dengan luas wilayah yang diawasi.

\section{KESIMPULAN DAN IMPLIKASI KEBIJAKAN}

\section{Kesimpulan}

a. Kelembagaan desa pada tiga masa pemerintahan memberikan peran yang menentukan bagi pengambil kebijakan, sebagai perencanaan pengelolaan sumber daya PUD di wilayah Sumsel maupun Desa Berkat. Transformasi pengelolaan PUD dengan berlakunya Perda OKI No. 9/2008, menunjukkan adanya peran masyarakat yang lebih besar dalam memanfaatkan sumber daya ikan.

b. Ketentuan di dalam Perda OKI No. 9/2008, memberikan kewenangan yang luas bagi Pemerintah Desa Berkat untuk mengatur pengelolaan lebak, lebung, dan sungai yang tidak dilelang secara mandiri, demi terciptanya kemakmuran desa.

\footnotetext{
${ }^{10} \mathrm{Hasil}$ wawancara dengan Sekretaris Desa Berkat (18 Juni 2009).

${ }^{11}$ Hasil wawancara dengan masyarakat dan Kepala Desa Berkat (18 Juni 2009).

${ }^{12}$ Hasil wawancara dengan masyarakat Desa Berkat (19 Juni 2009).

${ }^{13} \mathrm{Hasil}$ wawancara dengan masyarakat Desa Berkat (17 Juni 2009).

${ }^{14} \mathrm{Hasil}$ wawancara dengan aparat keamanan Desa Berkat (18 Juni 2009).
} 
c. Implementasi Perda OKI No. 9/2008 di Desa Berkat, menunjukkan bahwa proses sosialisasi serta komunikasi hukum belum berjalan dengan baik, karena kurangnya koordinasi dan pengontrolan oleh Pemerintah Daerah OKI; perbedaan pemahaman batas desa telah menimbulkan ketidakpastian bagi masyarakat; tidak optimalnya pelaksanaan penegakan hukum karena tidak ada aparat yang mendampingi satuan keamanan desa.

\section{Implikasi Kebijakan}

a. Pemerintah Kabupaten OKI perlu melakukan koordinasi dengan Pemerintah Desa Berkat untuk meningkatkan kapabilitas aparatur desa melalui pelatihan/ pendidikan, agar tugas dan fungsinya selaras dengan amanat diberlakukannya suatu peraturan. Memposisikan SDM sebagai human capital, membuat Desa Berkat mampu berdiri sendiri secara otonom dan aset yang dimiliki dapat dikelola dengan baik.

b. Pemerintah Daerah OKI wajib melaksanakan sosialisasi yang komprehensif kepada masyarakat, melakukan kontrol dan pendampingan secara konsisten, serta menciptakan komunikasi hukum yang terorganisasi dalam menjabarkan Perda OKI No. 9/2008. Hal ini dimaksudkan, agar setiap kendala yang timbul dengan berlakunya Perda OKI No. 9/2008, dapat diantisipasi dengan baik, serta mencegah terjadinya konflik akibat adanya perubahan aturan dan norma.

\section{DAFTAR PUSTAKA}

Abdurrahman, M. 2009. Sosiologi dan Metode Penelitian Hukum. UMM Press. Malang. 134 hal.

Cahyadi, A. dan D. Danardono. 2009. Sosiologi Hukum dalam Perubahan. Yayasan Obor Indonesia. Jakarta. 344 hal.
Hoebel, E.A. 2006, The Law of Primitive Man: A Study in Comparative Legal Dinamics. Cambridge, Mass., Harvard University Press. Los Angeles. 357 hal.

Husnah, S. Gautama, S. Nurdawati, E. Dharyati. 2006. Jenis, Cara Operasi dan Penyebaran Beberapa Alat Tangkap Ikan di Perairan Sungai Musi, Sumatera Selatan. Pusat Riset Perikanan Tangkap Badan Riset Kelautan dan Perikanan. Palembang. 53 hal.

Montesquieu. 2007. The Spirit of Laws. Nusamedia. Bandung. 463 hal.

Nasution, Z., N. Shafitri, P. Martosuyono, Mursidin, R. Pramoda, Muhadjir, A.M. Andrianto. 2009. Riset Panel Perikanan dan Kelautan Nasional (Panelkanas). Laporan Teknis. Balai Besar Riset Sosial Ekonomi - Kelautan Perikanan, Badan Riset Kelautan dan Perikanan, Kementrian Kelautan dan Perikanan, Jakarta. 137 hal.

Samidjo. 1986. Ilmu Negara. Armico. Bandung. 360 hal.

Scott, R.W. 2008. Institutions and Organizations: Ideas an Interest. Sage Publication. London. 280 hal.

Soekanto, S. 2008. Pengantar Penelitian Hukum. Penerbit Universitas Indonesia (UI-Press). Jakarta. 277 hal.

Widjaja, HAW. 2002. Pemerintahan Desa/ Marga: Berdasarkan Undang Undang No. 22 Tahun 1999 tentang Pemerintahan Daerah (Suatu Telaah Administrasi Negara). PT. Raja Grafindo Persada. Jakarta. 273 hal.

Yustika, A.E. 2006. Ekonomi Kelembagaan: Definisi, Teori, \& Strategi. Banyumedia Publishing. Malang. 364 hal.

\section{Undang-Undang dan Peraturan}

Peraturan Daerah Kabupaten Ogan Komering Ilir No. 9 Tahun 2008, tentang Pengelolaan Lebak, Lebung, dan Sungai dalam Kabupaten Ogan Komering Ilir, Lembaran Daerah Kabupaten Ogan Komering Ilir Tahun 2008 No. 9 
Undang-Undang Dasar 1945, Perubahan pertama disahkan 19 Oktober 1999, Perubahan kedua disahkan 18 Agustus 2000, Perubahan ketiga disahkan 10 Nopember 2001, Perubahan keempat disahkan 10 Agustus 2002

Undang-Undang No. 32 Tahun 2004, tentang Pemerintahan Daerah, Lembaran Negara Republik Indonesia Tahun 2004 No. 125
Undang-Undang No. 31 Tahun 2004, tentang Perikanan, Lembaran Negara Republik Indonesia Tahun 2004 No. 118, Tambahan Lembaran Negara Republik Indonesia No. 4433, sebagaimana telah diubah dengan UndangUndang No. 45 Tahun 2009, tentang Perubahan atas Undang-Undang No. 31 Tahun 2004, tentang Perikanan, Lembaran Negara Republik Indonesia Tahun 2009 No. 154, Tambahan Lembaran Negara Republik Indonesia No. 5073. 